\title{
STRUCTURAL BEHAVIOR OF REACTIVE POWDER REINFORCED CONCRETE SHORT COLUMNS
}

\author{
Ragheed F. Makki ${ }^{1}$ and Wafaa S. Naji ${ }^{2}$ \\ 1 Civil Engineering Department, University of Kufa, Iraq. E-mail: \\ ragheed.almutwali@uokufa.edu.iq
}

2 Civil Engineering Department, University of Kufa, Iraq. E-mail: wefaasalighalzuhairy@gmail.com

\section{HTTPS://DOI.ORG/10.30572/2018/KJE/130102}

\section{ABSTRACT}

The experimental work of this research included the test of seven columns, with dimensions of $900 \mathrm{~mm}$ length, and cross section $\left(150^{*} 150\right)$, a series of tests were carried out on control specimens (cylinder and prisms) for each mix for the purpose of studying the mechanical properties of reactive powder concrete such as compressive strength, splitting tensile strength, modulus of rupture and modulus of elasticity.

The experimental results showed the increasing in steel fibers ratio by $2 \%$ led to the increase in the compressive strength by $22 . r \%$ and increased splitting tensile strength by $329.7 \%$, modulus of rupture by $234.44 \%$ and modulus of elasticity by $20.80 \%$. The experimental results of the tests of slender columns indicated that increasing the steel fiber ratio from $0 \%$ led decreasing the ultimate load by $36.454 \%$ compared to the control columns, to $2 \%$ led increasing the ultimate load by $21.685 \%$ compared to the control columns. The results showed that of diameter steel reinforcement ratio of short columns from $\varnothing 10$ led to decreasing the ultimate load by $1.859 \%$ compared to the control columns, to $\varnothing 16$ led to increasing the ultimate load by $32.901 \%$ compared to the control columns. And the results showed that of spacing between of stirrups $(200 \mathrm{~mm})$ led to decreasing the ultimate load by $4.778 \%$ compared to the control columns, to $(100 \mathrm{~mm})$ led to increasing the ultimate load by $12.924 \%$ compared to the control columns.

In the second part of this research, the ANSYS program was used as a numerical method to investigate the behavior of these columns using nonlinear analysis (Finite element). When comparing the results of experimental with theoretical side ,the theoretical results showed a 
good agreement with the experimental results where the maximum difference ratio in ultimate load was about $9.03 \%$ for all the tested and analyzed columns.

KEYWORDS: Reactive Powder Concrete, Load Deflection, Steel Fiber Concrete, Silica fume, Steel reinforcement, Spacing between stirrups.

\section{INTRODUCTION}

One of the most significant structural elements is the compression member or column. In addition to moments, the column can be described as a columnar constructional part that supports and transfers axial loads. The cross-sectional dimensions of a column are usually less than its length. The vertical loads from the slabs are carried by the column and passed to the foundations (James, 2011).

Two methods of column reinforcement are used (longitudinal and transverse steel). Axial and flexural loads are carried by the main reinforcement (longitudinal reinforcement). Shear reinforcement (ties) resists shear stresses outside of the concrete, preventing or delaying buckling in the main rebar as a result of compression stresses. Additionally, to constrain the concrete in order to increase the concrete's strength capability (Jaafer, 2012). Two methods of column reinforcement are used (longitudinal and transverse steel). Axial and flexural loads are carried by the main reinforcement (longitudinal reinforcement). Shear reinforcement (stirrups) resists shear stresses outside of the concrete, preventing or delaying buckling in the main rebar as a result of compression loads (Campione et al., 2007). In compressed structural elements such as columns, high compressive strength is highly useful. When compared to regular strength concrete, the use of high strength concrete in columns reduces the dimensions of cross-sections while maintaining the same applied loads. The columns will become more slender as a result of this (Priyan 2003). When an increase in service loads occurs as a result of the installation of one or more additional floors during the construction phase, or when flaws in the design or building stage are discovered prior to use, or when a building is upgraded for new service uses, strengthening is applied (Frangou et al., 1995; Rahai and Alinia, 2008).

\subsection{Reactive Powder Concrete}

Yang et al., (2010) The structural behavior of UHPC beams exposed to bending was examined. Tests on fourteen rectangular beams were part of the experimental program. The dimensions of the beams were $180 * 270 * 2900 \mathrm{~mm}$. The amount of reinforcement and the type of casting were two of the experimental work's parameters. There were two symmetrical point 
loads applied. The longitudinal reinforcement in the beams was meant to be less than 0.02 . To investigate the behavior at low ratios, the tensile reinforcement ratio was $(0.006,0.009,0.012$, $0.0131,0.0196)$. The steel fibers utilized were straight and had a volumetric ratio of $2 \%$. The first approach was to place UHPC from one end of the form, whereas the second technique was to place UHPC from the mid-span of the form. According to the results of the experiments, casting the UHPC from one end provided better flexural resistance than casting from the mid span, so the casting method of the UHPC was affected on the flexural capacity with respect to the arrangement of the steel fibers. Steel fiber strengthened beam with low reinforcement ratio showed more ductile behavior because of the yielding of the bar.

Hannawayy, (2010) mechanical research characteristics of RPC, in addition the flexural behavior of RPC beams. The parameters of experimental program included the effect of steel fiber volumetric ratio $(0 \%, 0.5 \%, 1 \%, 1.5 \%$ and $2 \%)$ and silica fume content $(5 \%, 10 \%$ and $15 \%$ ) on some important mechanical characteristics of RPC such as uniaxial stress-strain, compressive strength, relationship in compression, modulus of rupture and splitting tensile strength. Additional experimental tests were also performed to study the influence of varying the ratios of the silica fume, steel fibers and reinforcing bars on the flexural behavior and load carrying capacity of singly reinforced rectangular RPC beams. The main reinforcing bars were nominal diameter 25, 16 and $12 \mathrm{~mm}$ were used, while the $10 \mathrm{~mm}$ diameter deformed steel bars were used as stirrup. The dimensions of beams were $140 \times 125 \times 1400 \mathrm{~mm}$ and all beams were simply supported and subjected to two symmetrical point loads until they failed. The result showed that when the volume fraction of steel fiber increased from $0 \%$ to $2 \%$ and silica fume from $5 \%$ to $15 \%$ led to increase the cylinder compressive by $38 \%$ and $16 \%$, splitting tensile strength by $162 \%$ and $14 \%$, modulus of elasticity by $280 \%$ and $8 \%$ andfailure load by $25.5 \%$ and $20 \%$ respectively, while increasing longitudinal reinforcement from zero to $8.7 \%$ led to increase the ultimate load by $766.67 \%$, so the longitudinal steel reinforcement plays an important role in predicting the bending capacity of RPC section. As fiber volume and longitudinal steel reinforcement increased, the cracking pattern and crack breadth in RPC grew in amount and dropped in width. He also discovered an equation for calculating nominal bending capacity.

In Adheem (2016) Under repeated loads, the mechanical characteristics and structural behavior of reactive powder concrete members were investigated. The inclusion of steel fibers to RPC improves the compressive strength, according to the findings of the experiments. The presence of steel fibers at volume frication $0.5 \%$ and $1 \%$ results in increasing the compressive 
strength by $10.8 \%$ and $30.02 \%$, consecutively, compared with RPC with steel fibers $0 \%$. The results also showed that raising the silica fume level from $15 \%$ to $25 \%$ increases compressive strength by just 6.88 percent and 11.61 percent, respectively, which is a smaller effect than adding steel fibers. The results also showed that increasing the steel fibers ratio from $0 \%$ to 0.5 and $1 \%$ increases the splitting tensile strength to (35.2 and 77.18$) \%$, respectively, while increasing the silica fume percentage from $15 \%$ to $20 \%$ and $25 \%$ increases the splitting tensile strength to (2.38 and 11.83$) \%$. In accordance with the experimental results, the adding of $0.5 \%$ and $1 \%$ volume fraction of steel fibers results in increasing the modulus of rapture of $49.88 \%$ and $96.41 \%$ consecutively, over nonfibrous RPC. Although silica fume shows little effect on the modulus of rupture. As silica fume ratio increases from $15 \%$ to $20 \%$ and $25 \%$, the modulus of rupture increases to $7.59 \%$ and $16.15 \%$ consecutively. When the volumetric content of steel fibers is increased from $0 \%$ to $0.5 \%$, the modulus of elasticity increases by $5.56 \%$ and $13.26 \%$, respectively. When the percentage of silica fume is increased from 15 percent to 20 percent and 25 percent, the modulus of elasticity increases by 0.8 percent and $3.58 \%$, respectively.

\subsection{Structural behavior columns}

Germain and Aspen (2005) An experimental and theoretical investigation of the behavior of high-strength columns was provided. All of the columns were slim, with hinges on both ends and eccentric uniaxial loading. Constant parameters were square cross- sections $(180 \mathrm{~mm})$, distance between stirrups $(140 \mathrm{~mm} \mathrm{c} / \mathrm{c})$, diameter of longitudinal steel bars $(12 \mathrm{~mm})$ and average compressive strength of cylinder ( $90 \mathrm{MPa}$ ) while variable parameters were slenderness ratio (72.7 and 84.3), end eccentricity (2, 5, 10 and $20 \mathrm{~mm}$ ) and diameter of stirrups $(6,8 \mathrm{~mm})$. In numerical study, experimental results compared with the results of the CEB finite differences (FD) and the CEB column model (CM) methods. The main conclusions reached the failure of slender HSC columns was influenced heavily by secondary moments, which provided a kind of structural ductility before the material failed. (FD) and (CM) methods were adequate to predict the ultimate load of slender HSC columns, but the (FD) method appeared more credible than (CM) to modeling the behavior of columns after post-peak.

Majewski et al., (2008) The failure of high and normal strength columns was simulated using a finite element approach. Those were unique columns (slender and short), hinged at both ends and applied uniaxial loading. (ABAQUS program) used in the non-linear FE analysis. Those FE-analyses (2D and 3D) results compared with all experimental results for (Kim and 
Yang). Parametric study were steel bar ratio, slenderness, load eccentricity, bond between concrete and steel bars (bond-slip or perfect-bond). The following are the main conclusions reached: 3D-FE results matched experimental results. When the steel bar ratio was high, 2DFE buckling strength findings were higher than experimental results. Buckling strength is improved when eccentricity and slenderness are reduced, but buckling strength is raised when the steel bar ratio is increased. When the bond-slip effect was added, the ultimate load increased in 2D simulations and dropped in 3D studies.

Leite et al., (2012) An experimental and theoretical study of the behavior of high and normal strength columns was presented. All of the columns were slender, pinned at both ends, and loaded uniaxially with uneven eccentricities at the ends. Constant parameters were total length $(3 \mathrm{~m})$, diameter of stirrups $(4 \mathrm{~mm})$ and distance between stirrups $(150 \mathrm{~mm} \mathrm{c} / \mathrm{c})$ while variable parameters were slenderness ratio (66.7 and 100), end eccentricity (e/h) $(0.1,0.2$ and 0.4$)$, ratio between eccentricities $(\beta=\mathrm{e} 1 / \mathrm{e} 2)(-0.5,0$ and 0.5$)$, longitudinal steel bars compressive strength of cylinder. In theoretical study, experimental results compared with the results of EC-2 (2004) and the ACI-318 (2008). The main conclusions reached: ultimate load is decreased for an increase of slenderness, end eccentricity ratio between eccentricities, while ultimate load is increased for an increase of compressive strength and longitudinal bars. A plastic hinge after ultimate load was produced when the column failed by tension while the column failed by compression was a brittle failure. The accuracy of EC-2 and ACI-318 in slender HSC columns was lower than in slender NSC columns.

\section{EXPERIMENTAL WORK}

\subsection{Experimental program}

All short columns have the same as the dimensions of cross section $(150 \mathrm{~mm} * 150 \mathrm{~mm})$ and $900 \mathrm{~mm}$ total length. It is designed using ACI318-14. Different longitudinal reinforcements were used as $(4 \varnothing 10 \mathrm{~mm}$ and $4 \varnothing 12 \mathrm{~mm}$ and $4 \varnothing 16 \mathrm{~mm})$. The ties reinforcement were distributed as $\varnothing 8 \mathrm{~mm}$ at quarter the both end which (@50mm) and the middle part reinforcement as Ø8mm (@100mm, @150mm and @ 200mm). Details of reinforcement are shown in Fig. 1. The columns are fixed-free supported at both ends. 

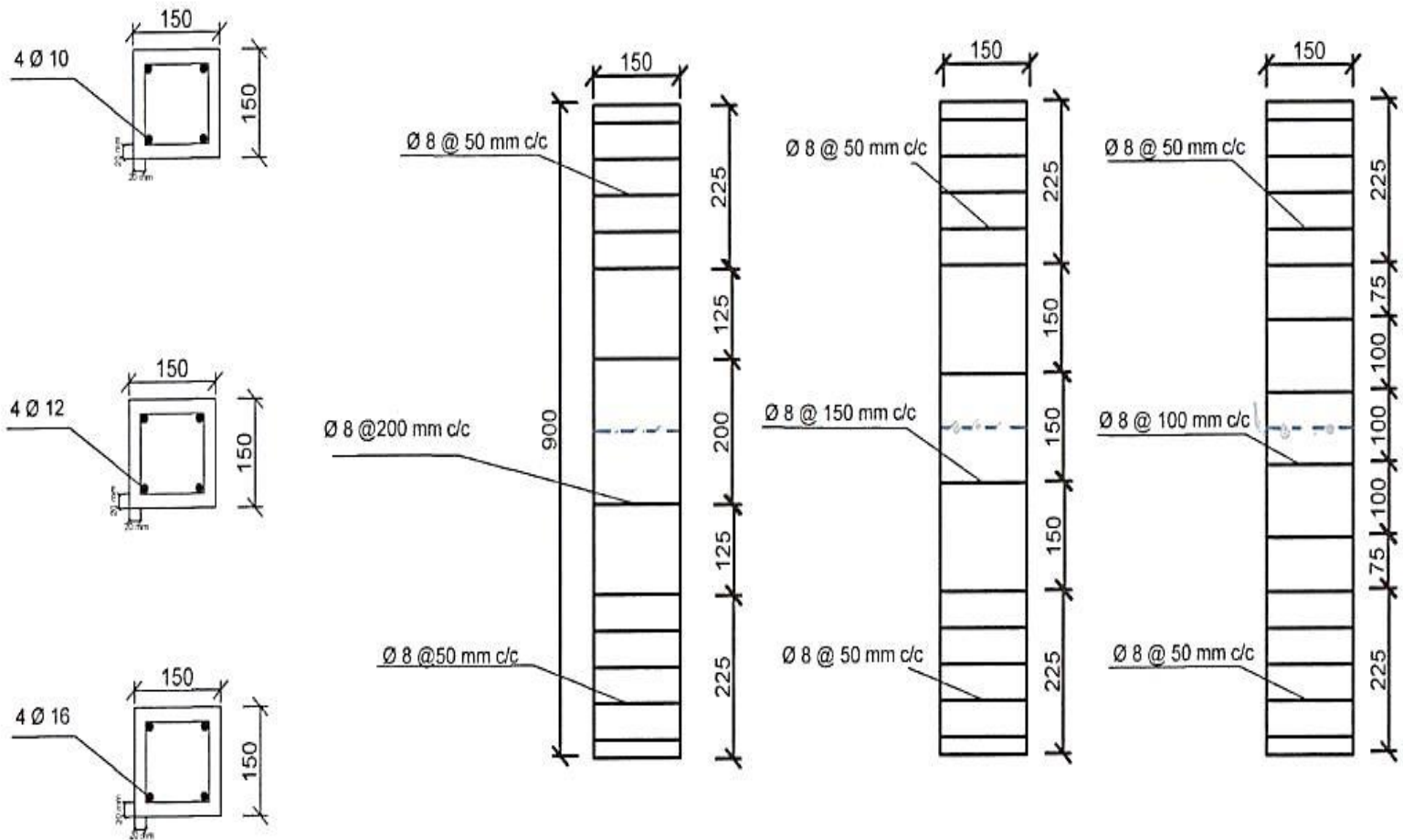

Fig. 1. The details of reinforcement distribution of slender column.

Table 1. The details of the tested slender column specimens.

\begin{tabular}{|c|c|c|c|c|c|}
\hline Group No. & $\begin{array}{c}\text { Steel } \\
\text { Fiber } \\
\text { (VF) } \\
\%\end{array}$ & $\begin{array}{c}\text { Silica } \\
\text { Fume } \\
\text { (SF)\% }\end{array}$ & $\begin{array}{c}\text { Longitudinal } \\
\text { Reinforcement } \\
\text { (AS) }\end{array}$ & $\begin{array}{c}\text { Shear } \\
\text { Reinforcement } \\
\text { (AV) }\end{array}$ & $\begin{array}{c}\text { Length Of } \\
\text { Column(mm) } \\
\text { (L) }\end{array}$ \\
\hline $\begin{array}{c}\text { SC1 } \\
\text { (control) }\end{array}$ & 1 & 15 & $4 \varnothing 12$ & $\varnothing 8 @ 150 \mathrm{~mm}$ & 900 \\
\hline SC2 & 0 & 15 & $4 \varnothing 12$ & $\varnothing 8 @ 150 \mathrm{~mm}$ & 900 \\
\hline SC3 & 2 & 15 & $4 \varnothing 12$ & $\varnothing 8 @ 150 \mathrm{~mm}$ & 900 \\
\hline SC4 & 1 & 15 & $4 \varnothing 10$ & $\varnothing 8 @ 150 \mathrm{~mm}$ & 900 \\
\hline SC5 & 1 & 15 & $4 \varnothing 16$ & $\varnothing 8 @ 150 \mathrm{~mm}$ & 900 \\
\hline SC6 & 1 & 15 & $4 \varnothing 12$ & $\varnothing 8 @ 200 \mathrm{~mm}$ & 900 \\
\hline SC7 & 1 & 15 & $4 \varnothing 12$ & $\varnothing 8 @ 100 \mathrm{~mm}$ & 900 \\
\hline
\end{tabular}

\subsection{Concrete mixes and steel bar reinforcement}

Reactive powder concrete consisting of cement, fine sand, silica fume, steel fibers, superplasticizers and water were used to cast the Reactive powder concrete columns, as well as the control specimens (cylinders, prisms) (ASTM C39/C39M, 2015; Maroliya, 2012; 
ASTM C496/C496M, 2011; ASTM C78/C78M, 2015; ASTM C469/C469M, 2014) of reactive powder concrete. Seven reactive powder concrete slender columns were casted in this study (SC1, SC2, SC3, SC4, SC5, SC6, LC7). Many mix proportions were tried to get maximum compressive strength according to ASTM C39/C39 M. Table 2 presents details of reactive powder concrete mix. And Deformed reinforcement for longitudinal and ties steel bar had been used. The diameter of $\varnothing 10 \mathrm{~mm}$ and $\varnothing 12 \mathrm{~mm}$ and $\varnothing 16 \mathrm{~mm}$ for longitudinal and $\varnothing 8 \mathrm{~mm}$ for ties reinforcement The test was carried out in the Referring Engineering Bureau University of Kufa's laboratory. Table 3 shows results of tensile test for all those bars used in study. The test results of bars (Ø $8 \mathrm{~mm}), \quad\left(\varnothing \frac{10 \mathrm{~mm}}{\varnothing}\right)$ $(\varnothing 12 \mathrm{~mm})$ and $(\varnothing 16)$ satisfy requirements.

Table 2. The details of reactive powder concrete mix components.

\begin{tabular}{|c|r|r|r|r|c|}
\hline $\begin{array}{c}\text { Cement } \\
\mathbf{K g} / \mathbf{m}^{3}\end{array}$ & $\begin{array}{c}\text { Silica } \\
\text { fume* } \\
\mathbf{K g} / \mathbf{m}^{3}\end{array}$ & $\begin{array}{c}\text { Sand } \\
\mathbf{K g} / \mathbf{m}^{3}\end{array}$ & $\begin{array}{l}\text { Steel } \\
\text { fiber** } \\
\%\end{array}$ & $\begin{array}{c}\text { w/c } \\
\% * * *\end{array}$ & $\begin{array}{c}\text { S.P.*** } \\
\end{array}$ \\
\hline 1000 & 15 & 1000 & 1 & 20 & 3.5 \\
\hline
\end{tabular}

* Silica fume was used as a replacement material.

** Percent of mix volume.

$* * *$ Water cement ratio is percent of cementitious materials (cement + silica fume).

$* * * *$ Superplasticizer is percent of cementitious materials (cement + silica fume).

Table 3. The properties of steel bar.

\begin{tabular}{|c|c|c|}
\hline $\begin{array}{c}\text { The diameter } \\
(\mathbf{m m})\end{array}$ & $\begin{array}{c}\text { Yield stress } \\
\text { (MPa) }\end{array}$ & $\begin{array}{c}\text { Ultimatestrength } \\
\text { (MPa) }\end{array}$ \\
\hline 8 & 513 & 648 \\
\hline 10 & 525.46 & 666 \\
\hline 12 & 545.24 & 696.27 \\
\hline 16 & 612 & 727 \\
\hline
\end{tabular}

*The modulus of elasticity for steel bars is assumed to $200000 \mathrm{MPa}$ 


\subsection{Test measurements and instrumentation}

In the structural laboratory of the College of Engineering at the University of Kufa, all specimens of reactive powder concrete columns were evaluated using a hydraulic machine (universal machine) with a maximum range capacity of 2000 kN. As shown in Fig. 2.

The columnar specimens were withdrawn from the water at the age of twenty-eight days, cleaned, and painted so that cracks could be easily detected before the testing day. The fixedfree status of column specimens was determined as shown in figure2. Bearing plates $(150 \mathrm{~mm}$ x $150 \mathrm{~mm} \times 16 \mathrm{~mm}$ ) were installed at both ends of the column to distribute stresses over the cross-section, as shown in figure 2. During the casting process, these plates were inserted in the ends of the columns. They were attached to keep the column from moving to the side during the test. There were no gaps between the plate and the concrete, ensuring that there were no concentration stresses on one side.

Two dial gauges were fitted when the specimen was placed on the hydraulic machine, one for vertical displacement and the other for horizontal displacement. 


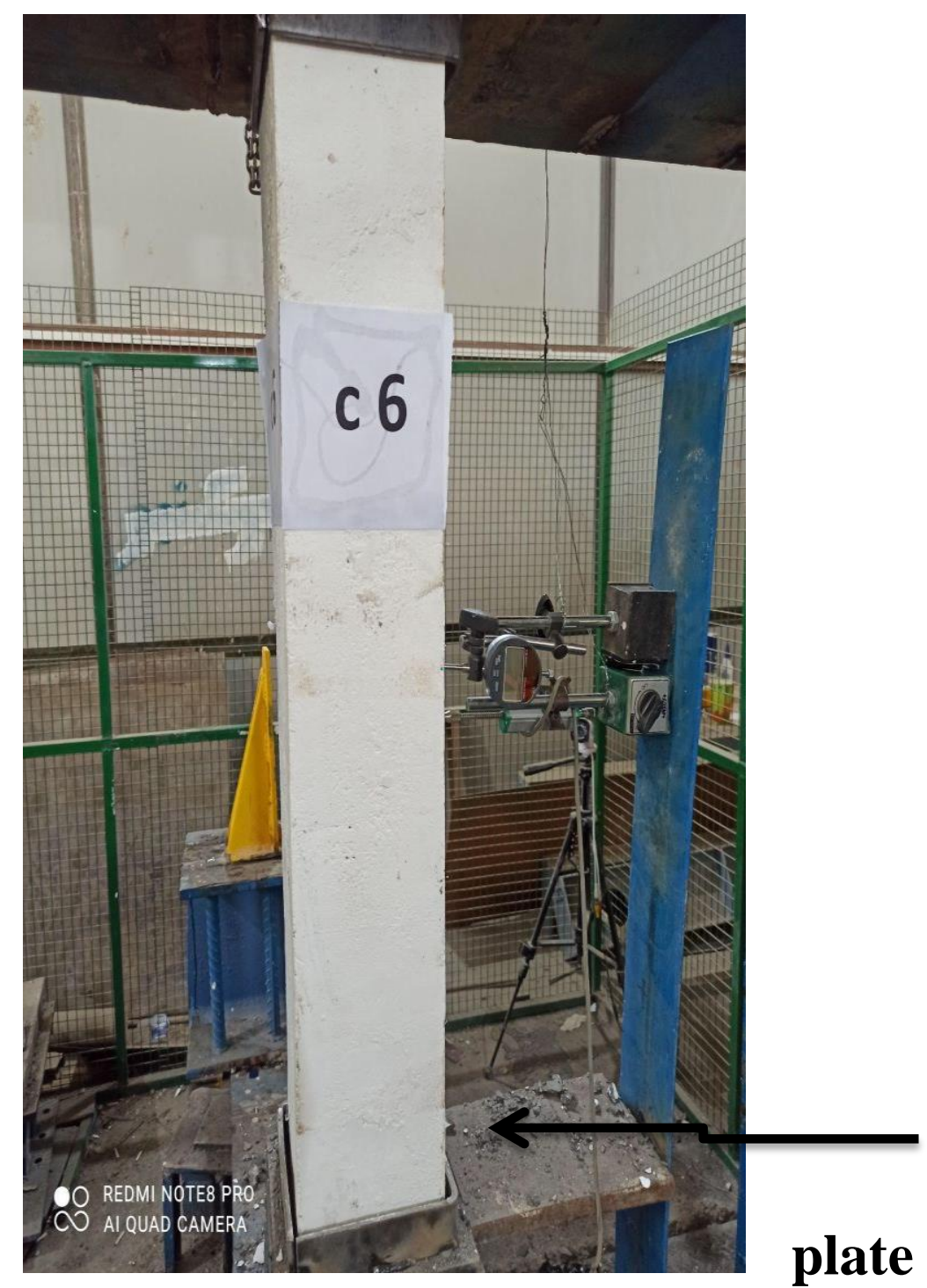

Fig. 2. The Testing of columns specimens.

\section{RESULTS AND DISCUSSION}

\subsection{The Short Column Control Specimen SC1}

The failure occurred at $(1263.5 \mathrm{KN})$ by cover spalling out at mid-height of column as shown in Fig. 3.

\subsection{The Short Column Control Specimen SC2}

The failure occurred at $(802.9 \mathrm{KN})$ by Cover spalling out at mid-height of column as shown in Fig. 4. 


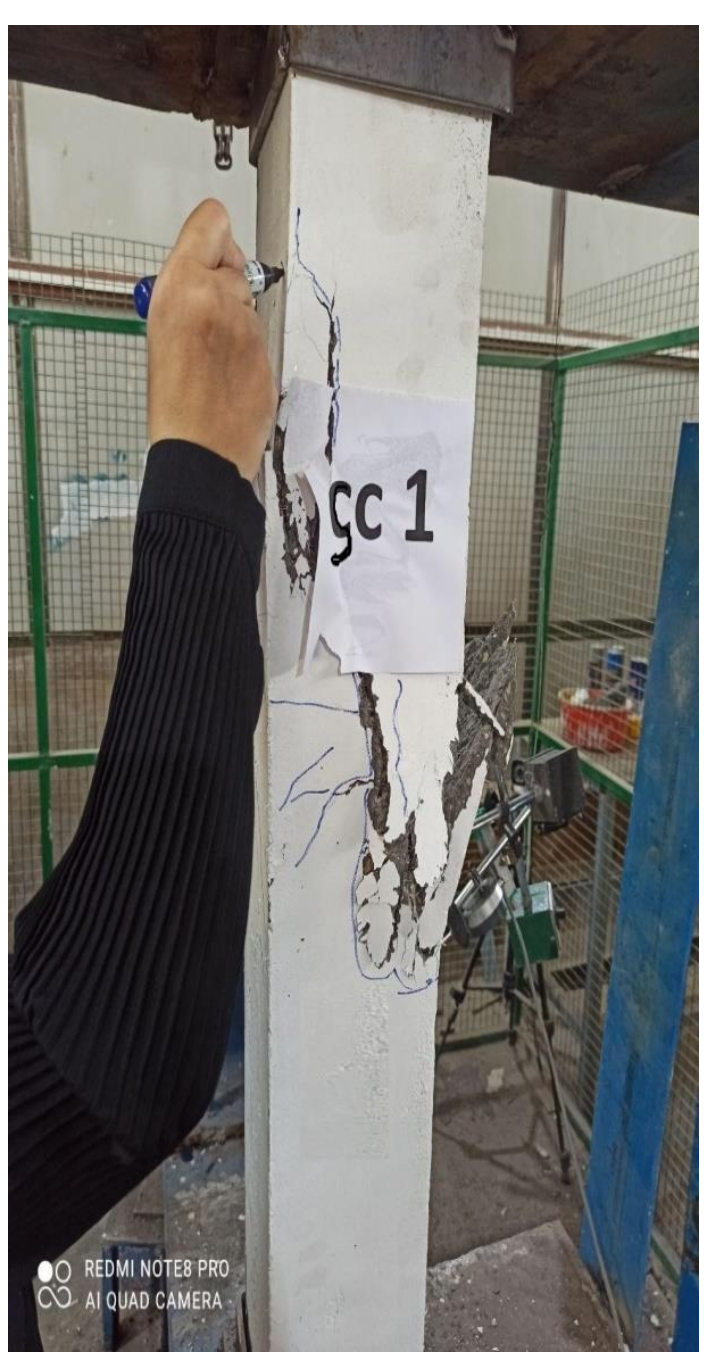

Fig. 3. The Testing of columns specimens SC1.

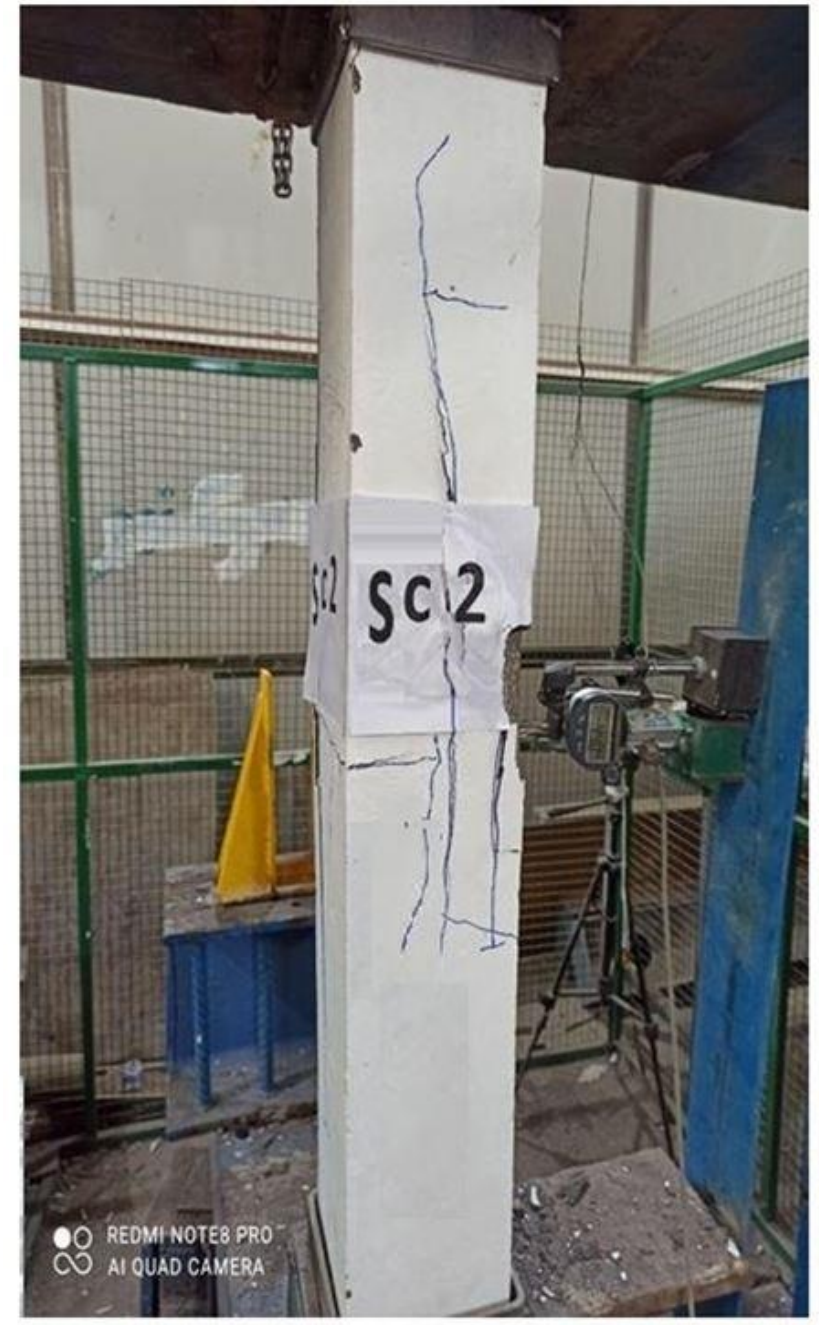

Fig. 4. The Testing of columns specimens SC2.

\subsection{The Short Column Control Specimen SC3}

The failure occurred at $(1537.5 \mathrm{KN})$ by buckling of reinforcing bar and Cover spalling out at ends as shown in Fig. 5.

\subsection{The Short Column Control Specimen SC4}

The failure occurred at $(1240 \mathrm{KN})$ by cover spalling out at ends as shown in Fig. 6. 

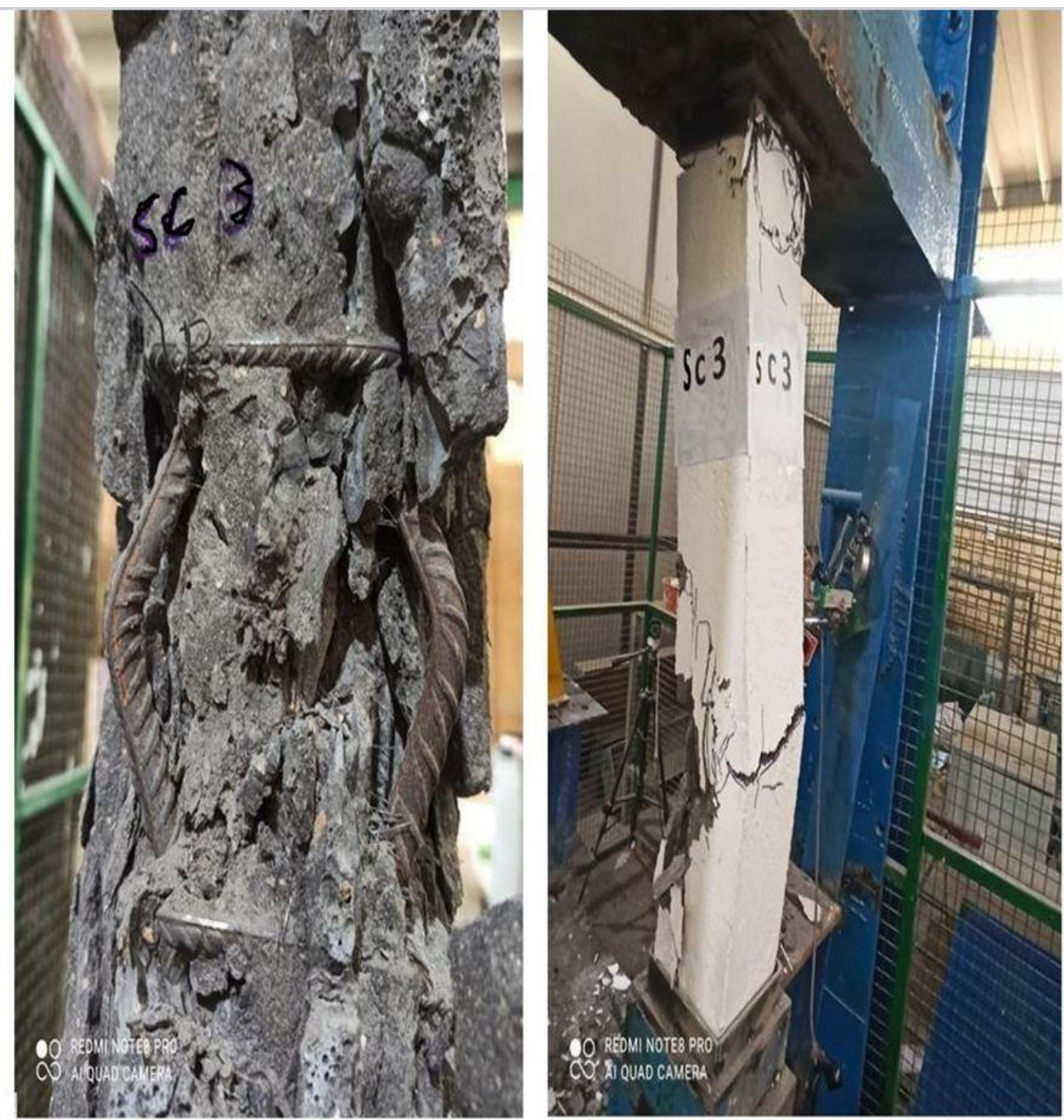

Fig. 5. The Testing of columns specimens SC3.

\subsection{The Short Column Control Specimen SC5}

The failure occurred at $(1679.208 \mathrm{KN})$ by cover spalling out at ends as shown in Fig. 7.

\subsection{The Short Column Control Specimen SC6}

The failure occurred at $(1203.12 \mathrm{KN})$ by cover spalling out at ends as shown in Fig. 8. 


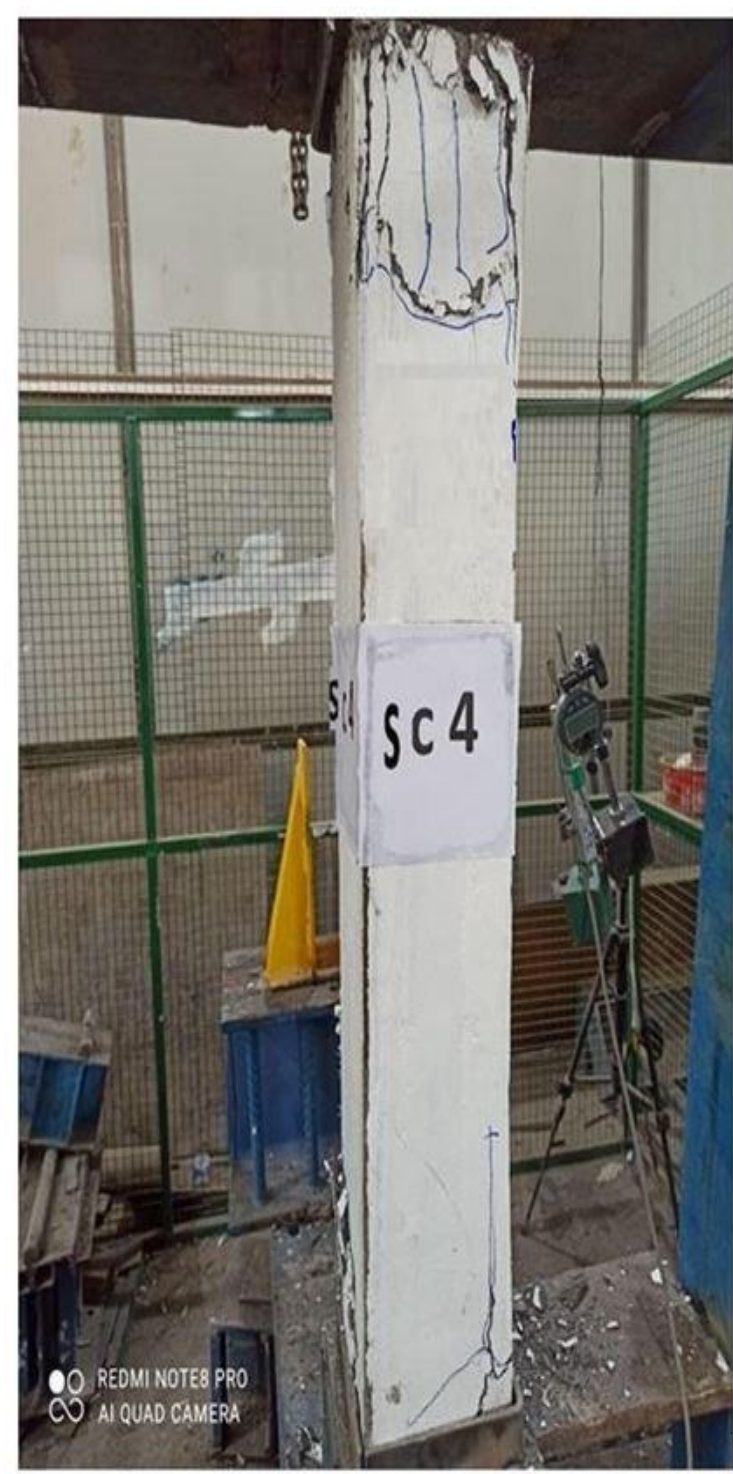

Fig. 6. The Testing of columns specimens SC4.

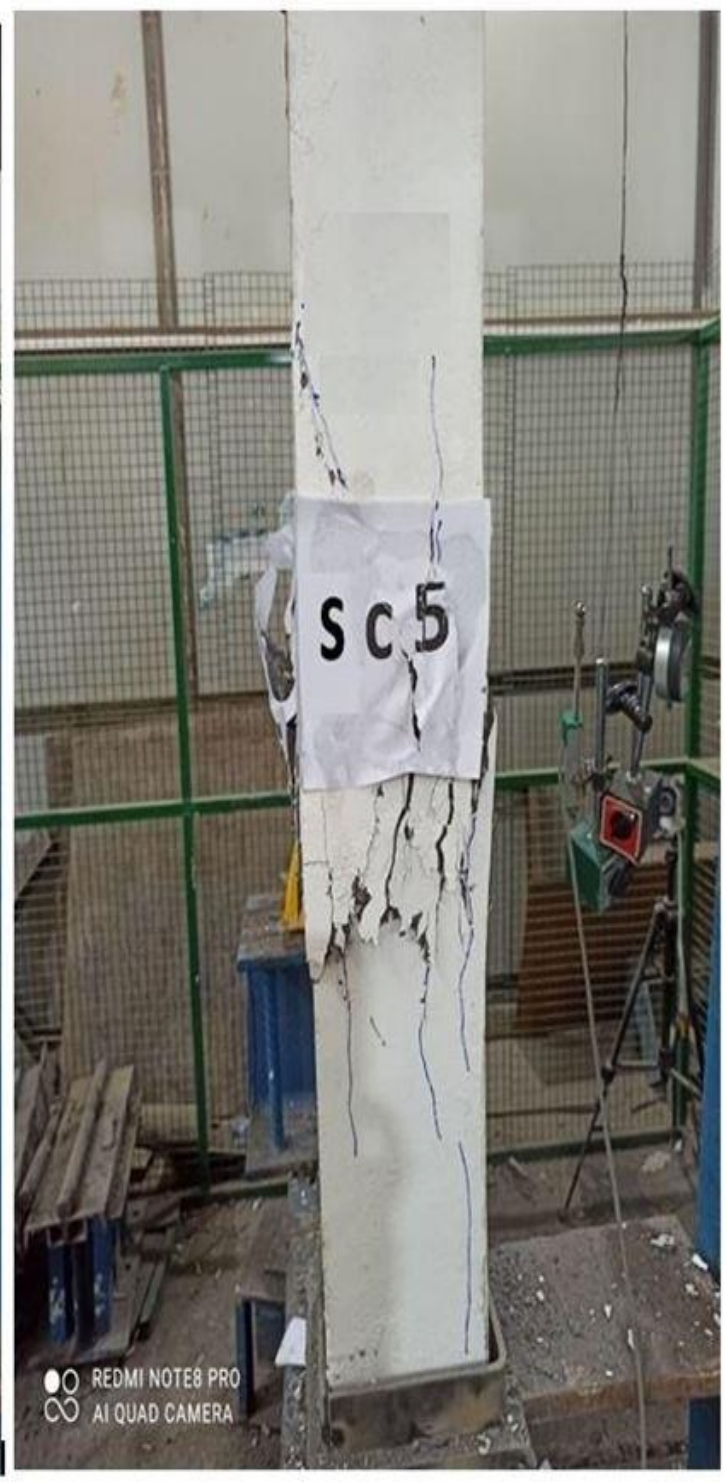

Fig. 7. The Testing of columns specimens SC5

\subsection{The Short Column Control Specimen SC7}

The failure occurred at (1426.8KN) by cover spalling out at ends as shown in Fig. 9. 

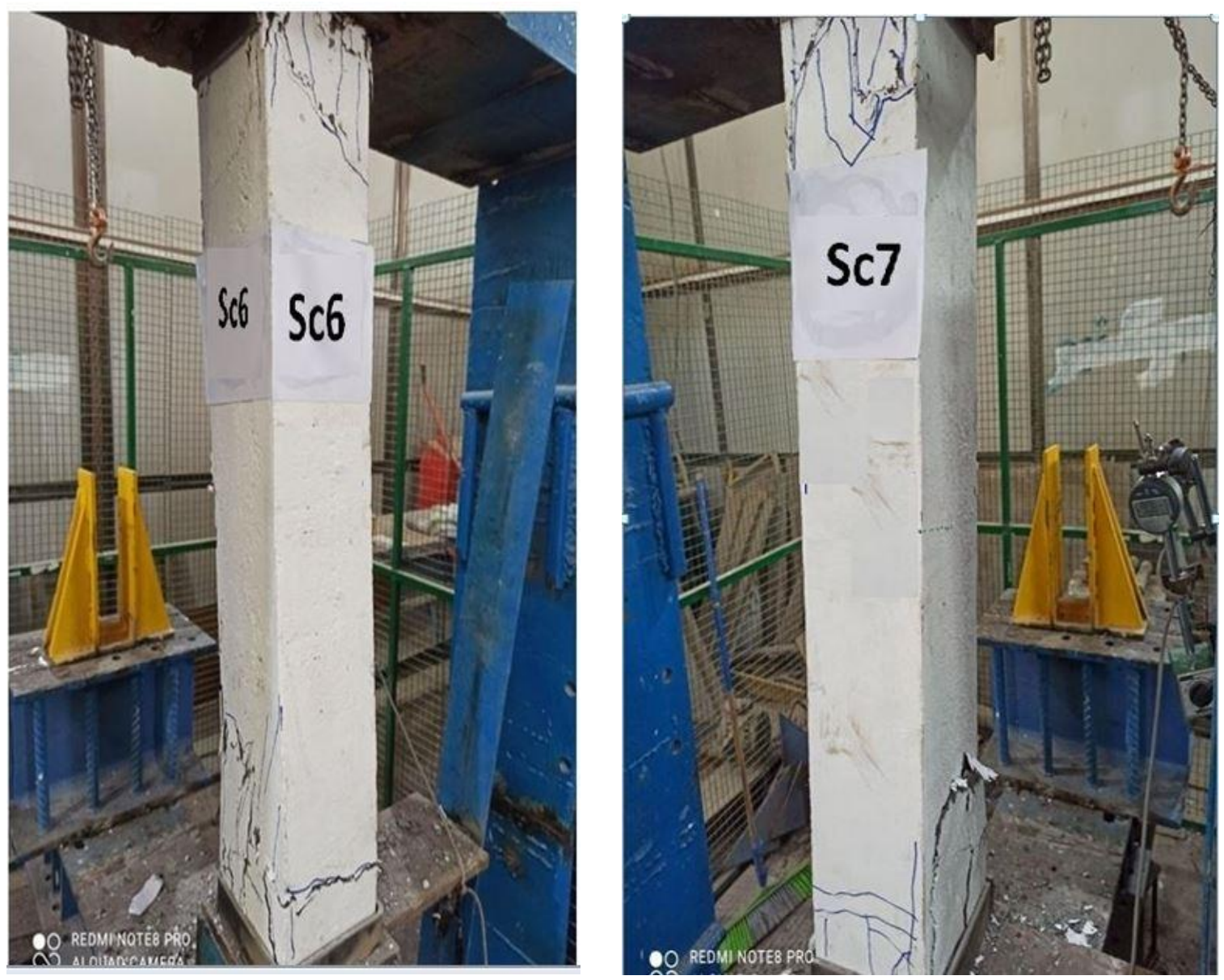

Fig. 8. The Testing of columns specimens SC6.

Fig. 9. The Testing of columns specimens SC7

\subsection{Ultimate load and deflection capacity}

Lateral displacements (deflections) were measured at the center of the face of the columns, in x-direction. The load versus deflection curves obtained from the numerical study (ALShimmari et al., 2011) together with the experimental studies plots are presented and compared in Figs. 10 to 16. In general, from the load-deflection plots, it can be noted that the finite element analysis agrees well with the experimental results throughout the full range of behavior. 


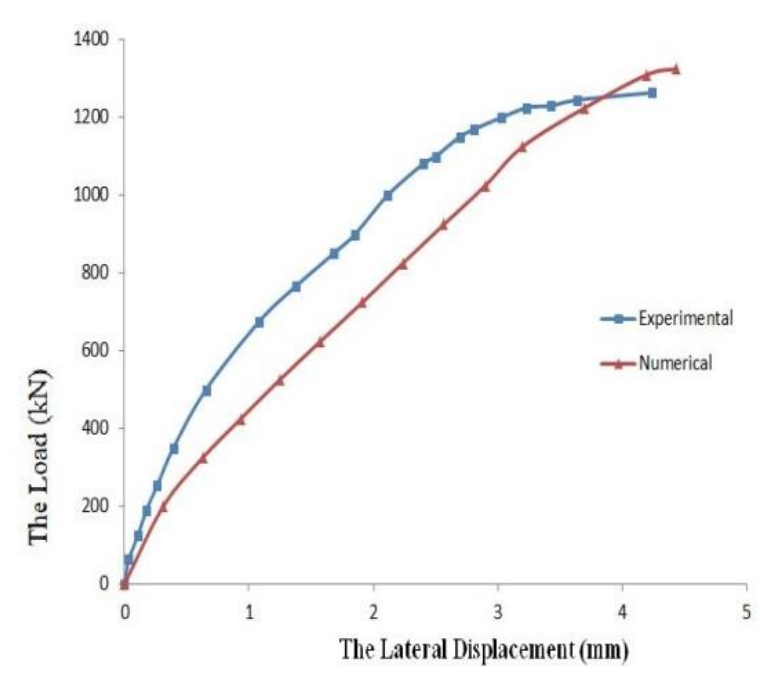

Fig. 10 Load-deflection curve of sc1.

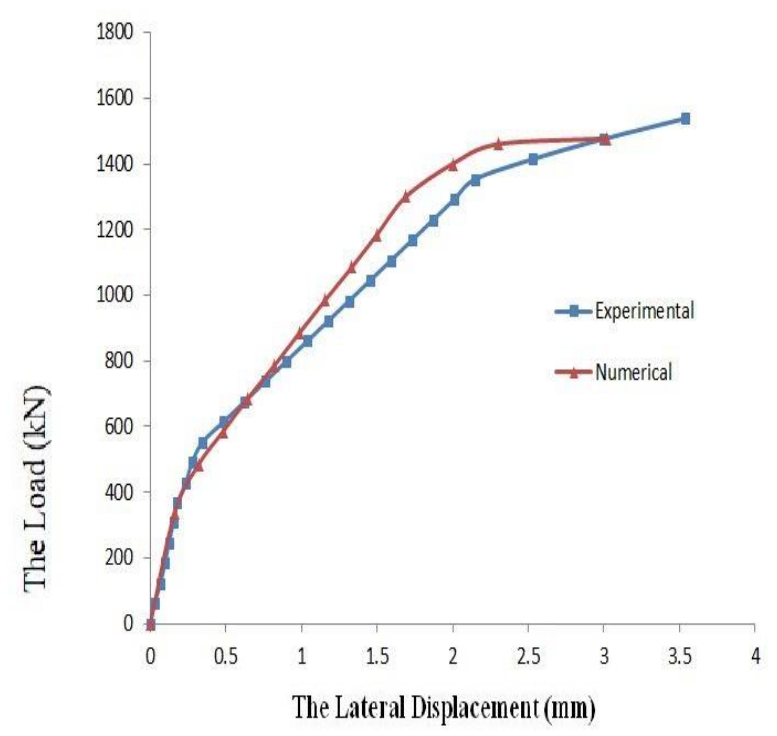

Fig. 12 Load-deflection curve of sc3.

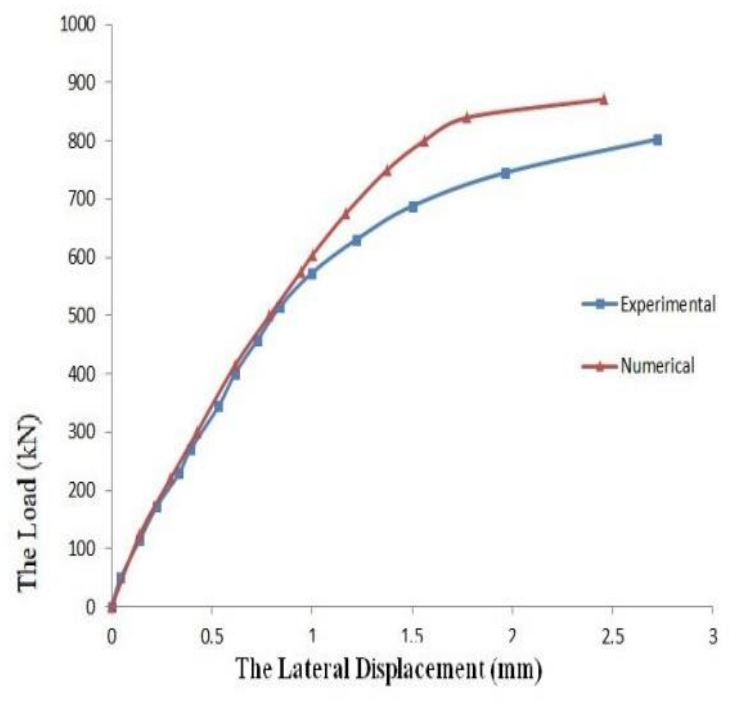

Fig. 11 Load-deflection curve of sc2.

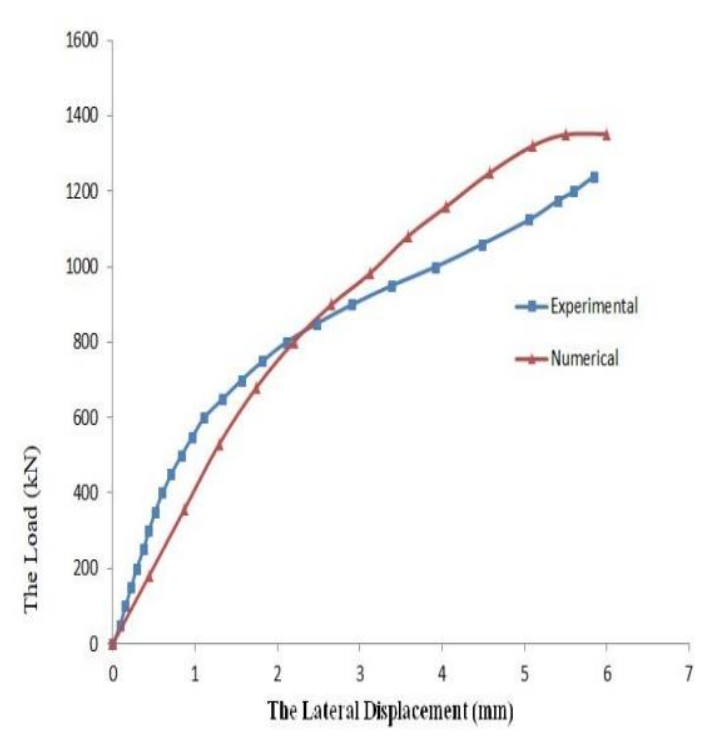

Fig. 13 Load-deflection curve of sc4. 

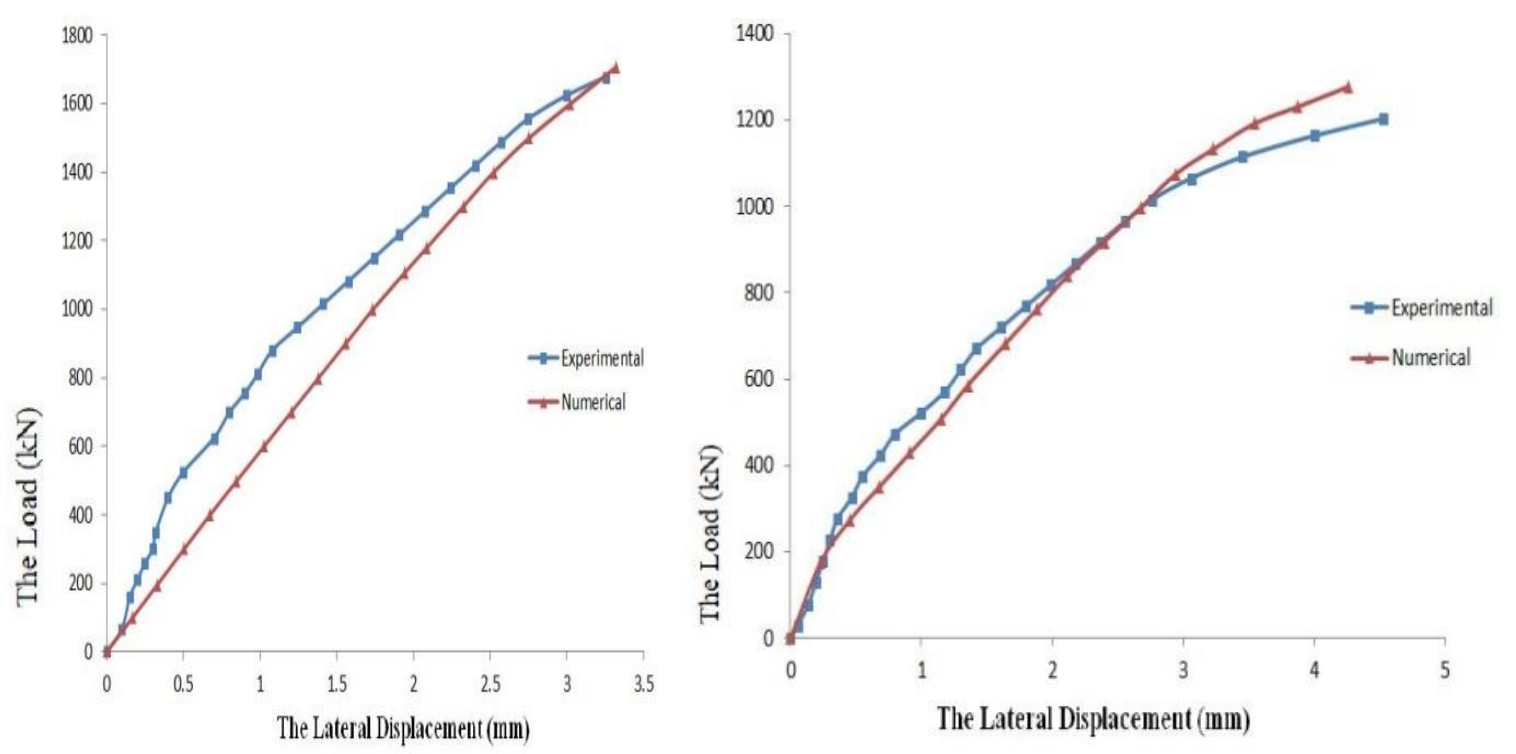

Fig. 14 Load-deflection curve of sc5. Fig. 15 Load-deflection curve of sc6.

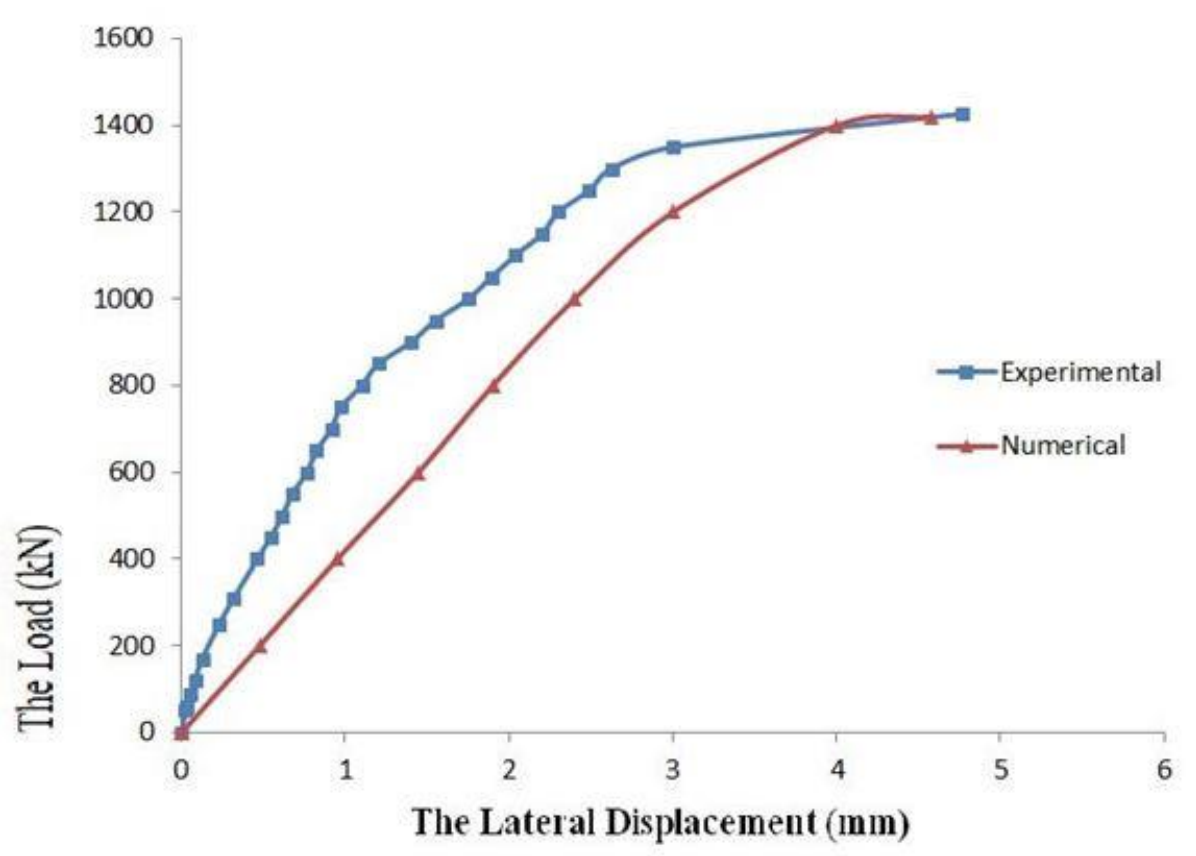

Fig. 16. Load-defletion curve of SC7

\subsection{Group One (The Changing Of Steel Fibers Ratio)}

Ultimate load was decreased by (36.454\%) for SC2 compared with SC1 (respect to the control short column) and ultimate load was increased (21.685\%) for SC3 with SC1 .The Fig. 10 shows the comparison of load-lateral deflection curves of column specimen SC2, SC3 and control specimen SC1. 


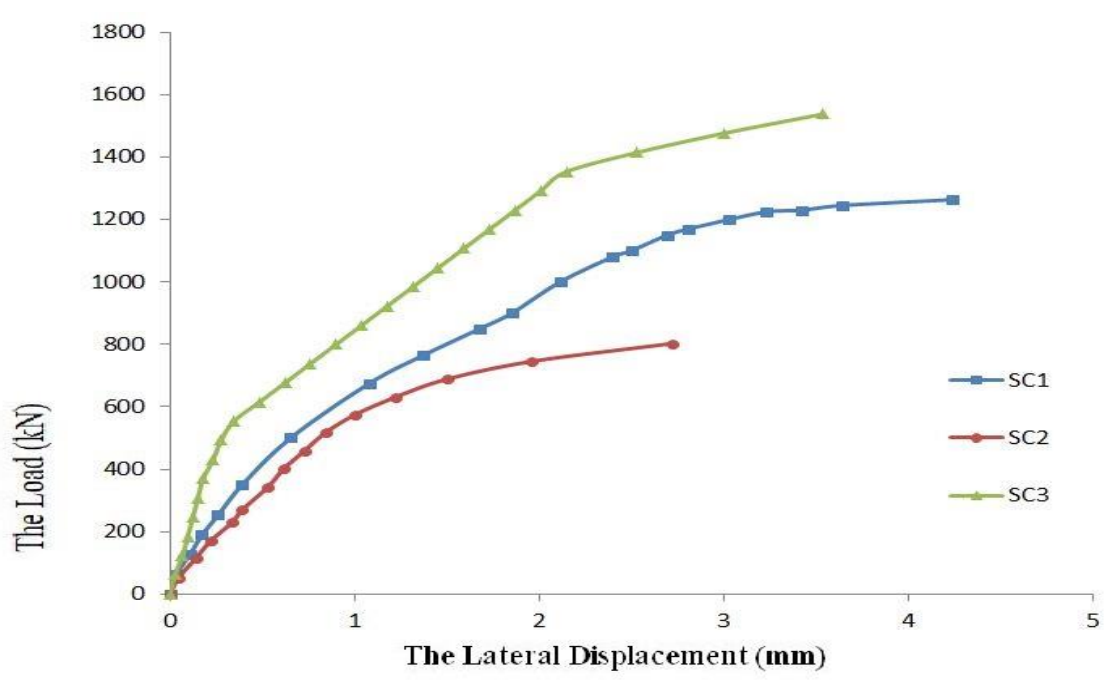

Fig. 10. The load -lateral deflection curves of SC2, SC3 and SC1 column specimens.

\subsection{Group Two(The Changing Of Longitudinal Steel Reinforcement)}

Ultimate load was decreased by (1.859\%) for SC4 compared with SC1 (respect to the control short column) and ultimate load was increased (32.901\%) for SC5 with SC1 .The Fig. 11 shows the comparison of load-lateral deflection curves of column specimen SC4, SC5 and control specimen SC1.

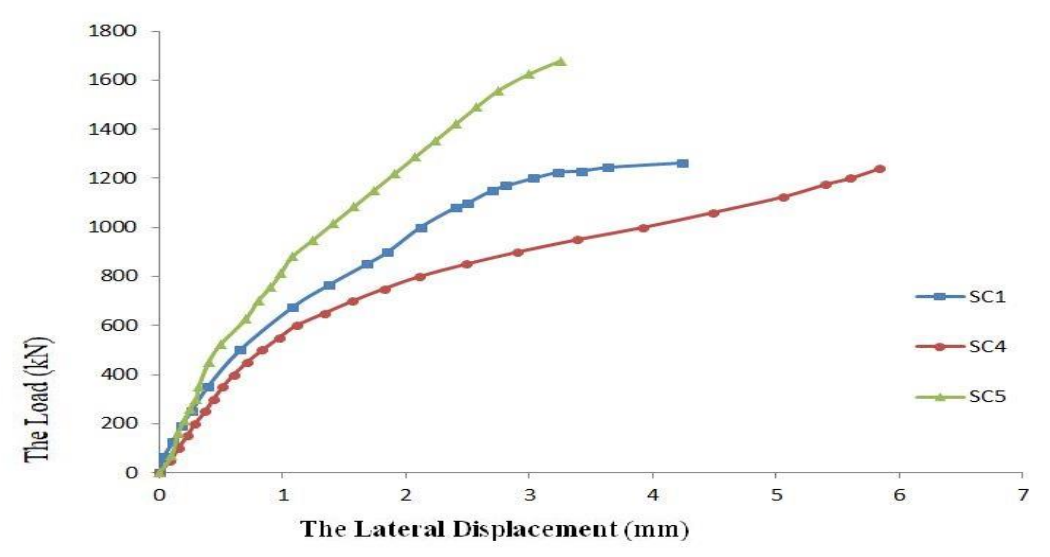

Fig. 11. The load-lateral deflection curves of SC4, SC5 and SC1 column specimens.

\subsection{Group Three (The Changing Of Spacing Between The Stirrups)}

Ultimate load was decreased by $(4.778 \%)$ for SC6 compared with SC1(respect to the control short column) and ultimate load was increased (12.924\%) for SC7 with SC1 .The Fig. 12 shows the comparison of load-lateral deflection curves of column specimen SC6, SC7 and control specimen SC1. 


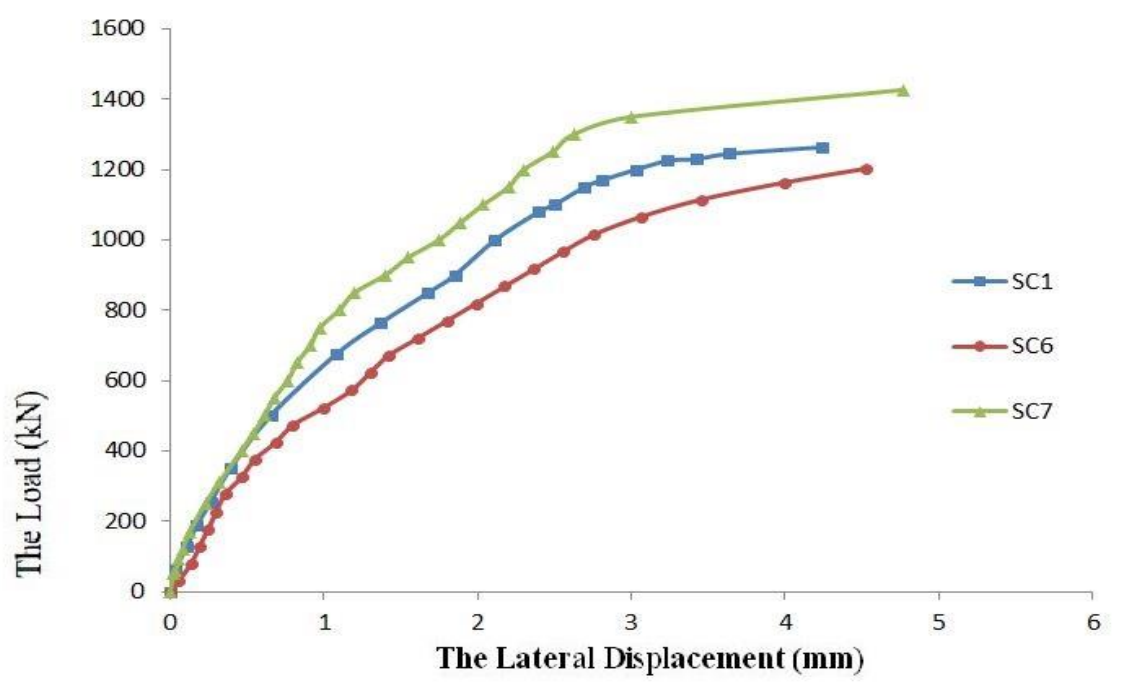

Fig. 12. The load-lateral deflection curves of SC6, SC7 and SC1 column specimens.

Table 4. Comparison between theoretical an experimental ultimate loads.

\begin{tabular}{|c|c|c|c|}
\hline \multirow{2}{*}{ Short column } & \multicolumn{2}{|c|}{ Ultimate load $(\mathrm{KN})$} & \multirow{2}{*}{$\begin{array}{c}\text { Pu)theo. } \\
\text { Pu)exp. }\end{array}$} \\
\cline { 2 - 3 } & Pu)exp. & Pu)theo. & 1.048 \\
\hline SC1 & 1263.5 & 1325 & 1.085 \\
\hline SC2 & 802.9 & 871.52 & 0.960 \\
\hline SC3 & 1537.5 & 1477 & 1.090 \\
\hline SC4 & 1240 & 1352 & 1.017 \\
\hline SC5 & 1679.208 & 1708 & 1.060 \\
\hline SC6 & 1203.12 & 1276.5 & 0.995 \\
\hline SC7 & 1426.8 & 1420 & \\
\hline
\end{tabular}

\section{CONCLUSIONS}

a. The non-linear finite element analysis by using ANSYS program of RPC columns is a powerful technique and can supply the researchers with valuable information. The crack patterns and ultimate loads predicted are close to that measured during the experimental testing.

2) The overall behavior of load- deflection curves represented from ANSYS program results showed a good correlation with the curves drawn from the experimental results.

3) When comparing the results of the experimental tests and theoretical side, the maximum difference in the ultimate load was $9 \%$ for the tested and analyzed columns. 
4) At final load, the crack patterns from the finite element model had a good match with the noticed failure of the experimental results.

\section{REFERENCES}

James K. W.," Reinforced Concrete Mechanics and Design ", Ph.d Thesis, University of Michigan, 2011.

Jaafer, A. A.," Behavior of Short Concrete Columns Strengthened with Ferrocement" Ph.D. Thesis, University of Basrah, 2012.

Campione, G., Colajanni, P., La Mendola, L., and Spinella, N., "Ductility of Reinforced Concrete Members Externally Wrapped with Fiber Reinforced Polymer Sheets", Journal of Composites for Construction, Vol. 11, No .3, pp. 279-290, 2007.

Priyan Mendis (2003), "Design of high strength concrete members: State-of- the-art". Published by John Wiley \& Sons, Inc.

Frangou M., Pilakoutas K. and Dritsos S. (1995), "Structural repair/strengthening of RC columns", Journal of Construction \& Building Materials, Vol. 9, No. 5, pp. 259-266.

Rahai A.R. and Alinia M.M. (2008), "Performance evaluation and strengthening of concrete structures with composite bracing members", Journal of Construction \& Building Materials, Vol. 22, No. 10, pp. 2100- 2110.

Yang, I.H., Joh, C., and Kim, B.S., "Structural Behavior of Ultra High- Performance Concrete Beams Subjected to Bending”, Engineering Structures, Vol. 32, 2010, pp.3478-3487.

Hannawayya, S.P., "Behavior of Reactive Powder Concrete Beams in Bending", Ph.D. Thesis University of Technology, Baghdad, October 2010, pp.239.

Adheem, A.H, . "Structural Behavior of Reactive Powder concrete member under Repeated loads”. Ph.D. Thesis, Babylon University, 2016,pp.202

Germain O. and Espion B. (2005), "Slender High-Strength RC Columns under Eccentric Compression”, Magazine of Concrete Research, Vol. 57, No. 6, pp. 361- 370.

Majewski T., Bobinski J., and Tejchman J., (2008) "FE Analysis of Failure Behaviour of Reinforced Concrete Columns under Eccentric Compression”, Journal of Structural Engineering, Vol. 30, No. 2, pp.300-317.

Leite L., Bonet J.L., Pallarés L., Pedro F. Miguel and Miguel A. Fernández- Prada (2013), "Experimental Research on High Strength Concrete Slender Columns Subjected to 
Compression and Uniaxial Bending with Unequal Eccentricities at the Ends", Journal of Engineering Structures, Vol. 48, pp. 220-232

ACI-318, "Building Code Requirements For Reinforced Concrete and Commentary", American Concrete Institute, Farmington Hills,Mich,USA, 2019.

ASTM C39/C39M (2015) . "Standard Test Method for Compressive Strength of Cylindrical Concrete Specimens”.USA: ASTM International ,pp.1-5.

Maroliya M. K., “A State Of Art- On Development Of Reactive Powder Concrete,” Int. J. Innov. Res. Dev., vol. 1, no. 8, pp. 493-503, 2012.

ASTM C496/C496M (2011) . “ Standard Test Method for Splitting Tensile Strength of Cylindrical Concrete Specimens ". USA: ASTM International, pp.1-5.

ASTM C78/C78M (2015). "Standard Test Method for Flexural Strength of Concrete (Using Simple Beam with Third-Point Loading)".USA: ASTM International ,pp.1-4.

ASTM C469/C469M (2014) . " Standard Test Method for Static Modulus of Elasticity and Poisson's Ratio of Concrete in Compression”. USA: ASTM International,pp.1-5.

AL-Shimmari I, Kh. , Hamad N.T. and Waryosh W.A. ,2011 . Investigation of the Behavior for Reinforced Concrete Beam Using NonLinear Three-Dimensional Finite Elements Model. Engineering College, University of Al-Mustansiriya/Baghdad ,Eng. \& Tech. Journal, 29(10), pp.1870-1885. 